\title{
BILINGUISMO ESCOLAR OU FAMILIAR? NOVAS EVIDÊNCIAS APONTAM PARA A IMPORTÂNCIA DO CONTEXTO ESCOLAR NO DESENVOLVIMENTO DO CONTROLE INIBITÓRIO
}

\author{
Luciana Brentano ${ }^{1}$ \\ Ana Beatriz Arêas da Luz Fontes ${ }^{2}$
}

\begin{abstract}
The positive effect of bilingualism on the development of children's cognitive functions has been shown across many recent studies in the field. The present study had two main objectives: (1) to replicate previous findings in the literature by showing bilinguals' enhanced inhibition control processes and, (2) to add new evidence to the field by demonstrating that school-based bilingualism can also enhance the process of inhibition control. To test these hypotheses, 59 students, ages 9 and 12, who were either monolingual, home-based bilinguals or school-based bilinguals, completed the arrow version of the Simon task, which assesses children's ability to deal with conflicting information, and thus, taps onto inhibition control processes. Results supported both hypotheses, such that school-based bilinguals performed better than monolinguals. Interestingly, school-based bilingual children also performed better than home-

1 Mestranda em Linguística Aplicada pela Universidade Federal do Rio Grande do Sul (UFRGS), Especialista em Ensino e Aprendizado de Língua Estrangeira pela UFRGS, Supervisora Pedagógica e Coordenadora do Currículo Bilíngue da Instituição Evangélica de Novo Hamburgo (IENH).

2 Profa. Dra. em Psicolinguística pela University of Texas at El Paso (UTEP) e bolsista de pós doutorado no PPG Letras da UFRGS.

Organon, Porto Alegre, ํำ51, julho-dezembro, 2011, p. 19-38
\end{abstract}


based bilinguals on the Simon task. These new findings are discussed in terms of the importance of a strong context for the onset of a bilingual advantage in cognitive functioning.

Keywords: bilingualism, cognitive development, inhibition control, school-based bilingualism, Simon task

\section{INTRODUÇÃO}

Nas últimas décadas muitos estudos sobre os processos cognitivos e linguísticos dos bilíngues foram conduzidos por um vasto grupo de pesquisadores (BIALYSTOK, 2004, 2005, 2006, ZELAZO, 2004, CARLSON e MELTZOFF, 2008, entre outros) interessados em investigar possíveis vantagens ou desvantagens no desenvolvimento cognitivo daqueles que aprendem e se comunicam em mais de uma língua. Entre os muitos motivos desse interesse está a necessidade de entender como as línguas são representadas na mente e no cérebro. De fato, a idéia de que o bilinguismo pode alterar significativamente o funcionamento cognitivo não é mais novidade; a novidade talvez esteja no fato de que os efeitos podem ser positivos (BIALYSTOK, 2010).

No que diz respeito ao bilinguismo infantil, é grande o número de investigações que comprovam que o uso diário de duas ou mais línguas leva a um desenvolvimento acentuado de certos processos cognitivos (como a atenção seletiva e o controle inibitório), linguísticos e metalinguísticos em comparação com crianças monolíngues de mesma faixa etária (BIALYSTOK, 2001, 2005, 2006; MARTIN-RHEE e BIALYSTOK, 2008).

Entretanto, a maioria desses estudos diz que tais vantagens são evidentes apenas quando se trata de crianças bilíngues nativas ou com proficiência avançada nas duas línguas faladas. A exemplo disso, citamos Carlson e Meltzoff (2008, p. 294) que em seu estudo justificam os resultados não satisfatórios com um grupo de imersão em segunda língua afirmando que "o padrão de descobertas sugere que o bilinguismo deve estar em um nível suficientemente alto para conferir vantagens detectáveis em tarefas cognitivas."

3 No original: (...) the pattern of findings suggests that bilingualism must be of a sufficiently high level to confer detectable advantage in cognitive tasks.

Organon, Porto Alegre, no 51 , julho-dezembro, 2011, p. 19-38 
Grande parte dos estudos que trata dos efeitos do bilinguismo nos processos cognitivos diz respeito às funções executivas, e principalmente ao controle inibitório (BIALYSTOK, 2005, 2010, CARLSON E MELTZOFF, 2008, POULIN-DUBOIS, et al., 2010). As funções executivas são importantes para o gerenciamento do comportamento humano. São elas que permitem não só o planejamento de ações e a tomada de decisões, mas, principalmente, o convívio em sociedade. As funções executivas são requisitadas sempre que são necessários planos de ação ou quando uma sequência apropriada de respostas precisa ser selecionada e organizada.

Tais habilidades executivas, segundo Diamond (2006), são cruciais para todas as formas de desempenho cognitivo. Por exemplo, o controle inibitório da atenção, evitando os fatores distratores, permite o desenvolvimento da atenção seletiva e sustentada. Da mesma forma, a habilidade de inibir uma forte inclinação de comportamento permite maior flexibilidade e possibilidade de mudanças. A inibição permite também uma medida de controle sobre nossa atenção e nossas ações a fim de que nosso comportamento não seja controlado por estímulos externos, emoções ou padrões arraigados.

Durante as últimas décadas, houve um grande crescimento no interesse pela investigação de aspectos relacionados à construção das funções executivas na infância, principalmente porque essas funções se desenvolvem muito rápido nessa fase e são essenciais para o pleno desenvolvimento social das crianças. O comprometimento do desenvolvimento das funções executivas pode causar situações problemáticas na escola e no convívio com outras pessoas, principalmente em relação à manutenção de informações na memória, à inibição de informações distratoras e ao direcionamento das ações do dia a dia (BLAIR, ZELAZO e GREENBERG, 2005).

Um dos fatores que pode alterar o desenvolvimento das funções executivas na infância é o bilinguismo. Recentes estudos têm mostrado que crianças bilíngues desenvolvem a atenção seletiva e o controle inibitório mais cedo do que seus pares monolíngues. Essa vantagem parece estar relacionada à necessidade constante de lidar com dois sistemas de linguagem ativos (GREEN, 1998). As evidências desse melhor desempenho dos bilíngues em tarefas que requerem atenção seletiva e controle inibitório têm sido reportadas em estudos envolvendo tarefas linguísticas (BIALYSTOK, 1986; CROMDAL, 1999) e também

Organon, Porto Alegre, nº 51, julho-dezembro, 2011, p. 19-38 
não linguísticas (BIALYSTOK, 2001, 2005; ZELAZO, MULLER, FRYE e MARCOVITCH, 2003). Nas seções seguintes, apresentamos alguns desses experimentos que evidenciam vantagens bilíngues tanto em tarefas de cunho linguístico como não linguístico.

\section{Tarefas Linguísticas}

As primeiras pesquisas relacionadas ao desenvolvimento metalinguístico de crianças bilíngues e monolíngues revelaram resultados contraditórios. Alguns estudos, como os de Bialystok (1988) e Cromdal (1999), mostraram desempenho equivalente para bilíngues e monolíngues em tarefas que exigiam capacidade para detectar violações gramaticais em frases com sentido. Além disso, alguns testes com foco no conhecimento de vocabulário reportaram baixos escores para bilíngues nas duas línguas em relação aos monolíngües em uma língua apenas (BIALYSTOK e CRAIK, 2011).

Uma tarefa, usada primeiramente por de Villiers e de Villiers (1972, apud BIALYSTOK, 2001b), deu origem a um experimento muito interessante desenvolvido por Bialystok e seus colegas. A tarefa consistia em introduzir uma informação enganosa em uma tarefa de julgamento de gramaticalidade, objetivando testar a atenção das crianças. A análise revelou um desempenho superior dos bilíngues em relação aos monolíngues na tarefa, pois os bilíngues demonstraram uma habilidade maior em ignorar as informações irrelevantes e se fixarem nas questões gramaticais da frase, sugerindo assim, que os bilíngues teriam mais facilidade em entender a arbitrariedade do signo. De qualquer forma, Bialystok deixa claro que este desempenho refere-se a uma tarefa metalinguística específica e não a uma vantagem global.

Tarefas como a de Julgamento de Gramaticalidade referida acima têm sido refeitas a fim de tornarem-se cada vez mais precisas e específicas na investigação da competência linguística e metalinguística das crianças. Já foram realizadas tarefas envolvendo alteração de detalhes, complexidade, estrutura das frases, entre outras (GALAMBOS e GOLDIN-MEADOW, 1990; GALAMBOS e HAKUTA, 1998; DE VILLIERS e DE VILLIERS, 1974; SMITH e TAGER-FLUSBERG, 1982; APUD BIALYSTOK, 2001b) e a maioria dessas tarefas mostra evidências de melhor desempenho por parte dos bilíngues.

Outro estudo que revelou que o conhecimento em segunda língua, mesmo que aprendido na adolescência, afeta a forma como as pessoas 
lêem na sua língua nativa é o de Van Assche et al. (2009). Na pesquisa, foram recrutados 45 falantes nativos de holandês que aprenderam inglês na idade de 14, 15 anos. A tarefa consistia em ler uma série de frases em holandês, algumas delas contendo palavras cognatas (palavras que compartilham forma e significado entre as línguas). Os pesquisadores observaram os movimentos dos olhos enquanto os sujeitos liam as frases e perceberam que os bilíngues despendiam, em média, oito milissegundos a menos ao ler palavras cognatas sugerindo que seu cérebro processa as palavras das duas línguas mais rapidamente do que palavras apenas encontradas em seu idioma nativo. A implicação mais importante do estudo é de que tornar-se bilíngue pode modificar o funcionamento cognitivo e o processamento da linguagem inclusive alterando as habilidades mais automáticas, como a leitura em língua nativa.

\section{Tarefas Não-Linguisticas}

É importante salientar que as diferenças nos processos cognitivos de bilíngues e monolíngues não se referem apenas às tarefas linguísticas, mas também têm sido encontradas em tarefas com problemas não verbais, como na tarefa do nível de água de Piaget (BIALYSTOK e MAJUMDER, 1998), no dimensional change card sort (DCCS, ZELAZO, 1985 e 2006), em tarefas de classificação (BIALYSTOK e MARTIN, 2004), em tarefas envolvendo a habilidade de ver imagens alternadas em uma figura reversível (BIALYSTOK e SHAPERO, 2005), entre outras.

Alguns dos estudos acima citados, conduzidos por Bialystok e seu grupo de pesquisa, têm mostrado que crianças bilíngues demonstram melhor desempenho do que monolíngues em tarefas que requerem o controle da atenção para inibir informações distratoras. Bialystok e Shapero (2005) relatam um estudo com 48 crianças de seis anos de idade (24 bilíngues e 24 monolíngues) cuja tarefa testava o controle sobre a atenção seletiva em relação a figuras ambíguas. Os resultados mostraram que os bilíngues obtiveram melhor desempenho que os monolíngues no teste, demonstrando maior facilidade em identificar o outro significado nas imagens ambíguas. Carlson e Meltzoff (2008) também encontraram evidências em suas pesquisas de que os bilíngues demonstram avançada habilidade em termos de controle inibitório se comparados com crianças monolíngues. No estudo relatado pelos autores, uma série de tarefas testando função executiva foi aplicada a um grupo de 50 crianças em idade pré-escolar de três grupos linguísticos

Organon, Porto Alegre, n 51, julho-dezembro, 2011, p. 19-38 
distintos: bilíngues nativos (inglês- espanhol), monolíngues (inglês) e falantes de inglês matriculados em um programa extracurricular de imersão em segunda língua. Os resultados mostraram que as crianças bilíngues nativas tiveram um desempenho significativamente melhor do que os outros dois grupos em tarefas que exigiam gerenciamento de conflitos. Outro estudo recente que apresentou benefícios cognitivos para crianças bilíngues foi conduzido por Poulin-Dubois, Blaye, Coutya e Bialystok (2010). Os autores aplicaram uma bateria de testes cognitivos em 63 crianças (bilíngues e monolíngues) e constataram diferenças vantajosas nas funções executivas de crianças de dois anos de idade.

O grau e o tipo de controle inibitório nos quais os sujeitos bilíngues demonstram tais vantagens diferem de estudo para estudo, dependendo do tipo de tarefa e das características dos sujeitos envolvidos nas testagens. Mesmo assim, essas vantagens foram evidenciadas em várias áreas, como por exemplo, criatividade, resolução de problemas e percepção não enraizada ${ }^{4}$ (BIALYSTOK, CRAIK, KLEIN e VISWANATHAN, 2004).

Tais evidências deixam claro que o bilinguismo proporciona algumas vantagens no processo cognitivo das crianças e de jovens adultos. Uma limitação dos estudos apresentados e conduzidos até então, entretanto, diz respeito ao tipo de indivíduo bilíngue participante das pesquisas. Na maior parte dos estudos, os sujeitos considerados bilíngues são apenas aqueles que adquiriram a segunda língua desde os primeiros anos de vida ou aqueles que vivem em uma comunidade na qual as duas línguas são faladas constantemente. Consideramos essa uma limitação dos estudos discutidos acima, pois nem sempre o contexto onde vivem os bilíngues se encaixa nessas duas realidades. Alguns estudos conduzidos no Brasil também focam no sujeito bilíngue como aquele falante de duas línguas desde a infância ou que tenha crescido falando as duas línguas na sua comunidade (FINGER et al, 2011; Bandeira, 2010).

Existem muitas medidas para considerar um sujeito bilíngue, entretanto, os bilíngues escolares provenientes do contexto educacional - modalidade esta que vem crescendo no Brasil - não têm recebido espaço nas pesquisas cognitivas. Segundo levantamento feito por Lyle Gordon French, diretor de uma escola bilíngue em São Paulo, hoje em dia já contamos com uma média de 180 escolas bilíngues no Brasil, sendo 127 destas só na capital paulista (Brentano, 2009).

4 No original: "perceptual disembedding" (BIALYSTOK, CRAIK, KLEIN \& VISWANATHAN, 2004: 290). 
A nosso ver, existe uma lacuna na literatura no que se refere à investigação sobre os efeitos cognitivos do bilinguismo escolar. É justamente nesse contexto que se insere o estudo relatado neste artigo, o qual teve como objetivo investigar em que medida o bilinguismo escolar afeta o desenvolvimento cognitivo das crianças de 9 a 12 anos, da mesma forma como tem sido atestado na literatura no caso de bilinguismo societal ou familiar. A fim de contribuir com as pesquisas na área da cognição bilíngue, o presente artigo tem por objetivo apresentar dados preliminares de um estudo conduzido com 59 crianças, de 9 e 12 anos, pertencentes a três grupos linguísticos diferentes: falantes monolíngües de português, bilíngues português- hünsrickisch inseridos em uma comunidade bilíngue e bilíngues português-inglês inseridos em contexto de escolarização bilíngue.

Este estudo teve como objetivo principal investigar possíveis diferenças entre crianças monolíngues e bilíngues em uma tarefa de controle inibitório, como atestado em estudos anteriores. Para isso, foram consideradas crianças advindas de contextos bilíngues distintos - contexto familiar, ou bilíngues de casa, e contexto escolar, ou bilíngues de escola - a fim de avaliar se o contexto de aquisição da segunda língua desempenha algum papel no desenvolvimento do controle inibitório.

As hipóteses que nortearam esta pesquisa foram as de que falantes bilíngues possuem melhor controle inibitório em tarefa não linguística do que monolíngues, e que bilíngues de escola possuem controle de inibição tão eficaz quanto os bilíngues de casa. Essas hipóteses foram baseadas em estudos anteriores que evidenciaram a habilidade dos bilíngues em lidar com dois códigos linguísticos, demonstrando melhor desempenho nessas funções.

\section{METODOLOGIA}

\section{Participantes}

Participaram desta pesquisa 59 crianças, divididas em três grupos lingüísticos, sendo que cada grupo foi também dividido em duas faixas etárias:

1. 19 crianças bilíngues de casa, falantes de português e de hünsrickisch: 6 crianças de 9 anos (4 meninos e 2 meninas), e 13 crianças de 12 anos (6 meninos e 7 meninas);

Organon, Porto Alegre, nº 51, julho-dezembro, 2011, p. 19-38 
2. 27 crianças bilíngües de escola (ou seja, alunos de uma escola de currículo bilíngüe), falantes de português e inglês: 14 crianças de 9 anos ( 9 meninos e 5 meninas) e 13 crianças de 12 anos (6 meninos e 7 meninas);

3. 13 crianças monolíngües, falantes de português: 8 crianças de 9 anos ( 5 meninos e 3 meninas) e 5 crianças de 12 anos (todos meninos).

As crianças de contexto familiar bilíngue português-alemão estudam em uma escola que atende um público de classe A e B no município de Picada Café, RS. A escola funciona no turno da manhã ou da tarde e os alunos possuem uma carga horária de 20 horas semanais, todas em língua portuguesa. $\mathrm{O}$ alemão formal ocorre uma vez por semana como aula especial na escola. Os alunos deste contexto estão em contato com o alemão dialeto (hünsrickisch) desde o nascimento e falam o mesmo em casa com os avôs, que em sua maioria moram no mesmo terreno. Por vezes utilizam hünsrickisch na escola ao conversarem com os amigos. Um dado interessante relatado frequentemente nas entrevistas é que gostam tanto do português quanto do hünsrickisch, e sentem orgulho em falar esta língua que foi ensinada pela família.

As crianças que estão inseridas em contexto escolar bilíngue português-inglês estudam em uma instituição de ensino localizada na cidade de Novo Hamburgo, RS, que atende alunos, em sua maioria, de classe A e B da região. São crianças com nível linguístico, cultural e social privilegiado. É uma escola muito exigente no que se refere à formação dos professores, dos alunos e com os valores que perpassam os conteúdos. As crianças que pertencem a esse contexto possuem uma carga-horária escolar semanal de 30 horas, sendo que 10 horas são ministradas na língua inglesa. Foram selecionadas para este estudo crianças que já estudam nesse currículo há pelo menos cinco ou seis anos.

Finalmente, as crianças monolíngues estudam em uma escola estadual que atende um público de classe $\mathrm{B}$ e $\mathrm{C}$ do município de Novo Hamburgo. São crianças de nível social e acesso cultural um pouco inferior aos dos outros grupos. Nesse contexto, as crianças estudam 20 horas semanais na língua portuguesa. O grupo de alunos de 12 anos possui um período semanal de língua estrangeira (inglês), mas, conforme relatos, é uma aula que não acontece em inglês. Através dos questionários foi possível verificar que nenhum dos sujeitos tinha contato com aulas de inglês ou outra língua no turno oposto ao de ensino. 
Tarefa e Materiais

No estudo, os participantes realizaram a Tarefa Simon de flechas contendo flechas de controle e flechas laterais em um notebook HP que possuía o software E-prime 2.0. Na condição de controle foi adotado o estímulo de flechas à esquerda e flechas à direita, apresentadas no centro da tela do computador. Para responder ao estímulo, os participantes precisavam pressionar a tecla "1" se a flecha estivesse apontando para a esquerda e a tecla " 0 " se a flecha estivesse apontando para a direita. Foram apresentados 24 estímulos no centro da tela e cada estímulo era precedido por uma cruz, que aparecia no centro da tela e ali permanecia por $800 \mathrm{~ms}$, e por um intervalo em que a tela ficava em branco por $250 \mathrm{~ms}$. Após a aparição da cruz e do intervalo com a tela em branco, uma flecha na cor vermelha apontando para um dos lados aparecia e permanecia na tela até que o participante pressionasse a tecla " 1 " ou a tecla " 0 ".

$\mathrm{O}$ estimulo de flechas foi utilizado com o objetivo de isolar o componente cognitivo de controle inibitório da memória de trabalho, pois responder ao estímulo de flechas no centro da tela não exige grande esforço do participante para lembrar-se da associação entre estímulo e a tecla de resposta (BILLIG, 2009). Isso porque a associação entre estímulo e a tecla de resposta é direta (flecha apontando para o lado direito requer que se pressione o botão da direita e vice versa) e por isso não exige controle, apenas atenção e acurácia.

A outra condição utilizada foi de flechas laterais. Nessa condição, apareciam 48 estímulos, sendo 24 estímulos congruentes (posição na tela e tecla de resposta no mesmo lado) e 24 estímulos incongruentes (posição na tela e tecla de resposta em lados opostos) aparecendo na tela de forma aleatória. $\mathrm{O}$ fato de os estímulos não aparecerem no centro da tela exige a seleção de maior atenção para o estímulo. Conforme Gawryszewski e colaboradores (2006), um estímulo localizado à esquerda projeta-se para o hemisfério direito, o qual controla a mão esquerda. Da mesma forma, um estímulo localizado à direita projetase para o hemisfério esquerdo, o qual controla a mão direita. Assim, o teste exigiria muito mais esforço da criança em termos de atenção e também controle inibitório, para inibir o desejo de utilizar a mão esquerda, por exemplo, quando o estímulo estivesse do lado esquerdo da tela, mas apontando para o lado direito.

Antes de cada teste, os participantes realizavam uma sessão de prática, nos mesmos moldes do teste. Para que os participantes pudessem 
realizar o teste era necessário que obtivessem cem por cento de acerto na sessão de prática.

\section{Design}

O experimento foi do tipo 3 (congruência) X 3 (grupo linguístico) $\mathrm{X} 2$ (idade) Mixed Design. A Congruência foi manipulada como uma variável entre sujeitos do mesmo grupo, enquanto grupo linguístico e idade agiram como variáveis entre sujeitos de grupos diferentes. Foi medido o tempo de resposta e a acurácia dos participantes. Neste artigo, entretanto, apresentamos apenas os resultados referentes ao tempo de resposta, por limitação de esp aço.

\section{Procedimentos}

Após o contato com a equipe pedagógica das escolas a fim de obter a autorização para a realização da pesquisa, foi enviado para as famílias o termo de consentimento informado, a fim de que as crianças pudessem ser autorizadas a participar da testagem. Além do termo, as famílias também receberam um questionário de informações pessoais e histórico de linguagem, que informou a seleção da amostra. A partir das informações obtidas fez-se a seleção da amostra, garantindo, assim, que as crianças que compunham o grupo de monolíngues não estudassem inglês fora da escola nem possuíssem bilíngues na família, que o grupo de bilíngues de casa realmente falassem alemão/ hünsrickisch com as famílias, e que os bilíngues escolares realmente tivessem contato diário com a segunda língua somente na escola. A seguir, foram agendadas com as professoras das turmas as datas de aplicação dos testes de forma a não atrapalhar o andamento das atividades escolares.

No dia da testagem, cada sujeito foi testado individualmente, em português, em uma sala reservada da escola. Cada teste durava em torno de 2 a 3 minutos. O sujeito era recebido na sala e convidado a sentar em frente à tela de um laptop, próximo à pesquisadora. Primeiramente se estabelecia um diálogo de interação entre pesquisadora e sujeito com o intuito de deixá-lo menos ansioso com a testagem. Nesse momento, a pesquisadora esclarecia algumas informações que não haviam ficado evidentes no questionário, perguntando, em especial, sobre interações com a língua foco. Após, era explicado ao sujeito cada teste, à medida que eles iam aparecendo na tela.

Organon, Porto Alegre, nํ51, julho-dezembro, 2011, p. 19-38 
O Teste Simon de flechas controle sempre era aplicado antes do teste Simon de flechas laterais. O primeiro durava em torno de 2 minutos e era explicado para as crianças de forma simples e clara: "O teste que tu vais fazer agora é um teste de flechas. As flechas aparecerão no centro da tela. Quando a flecha aparecer na tela e apontar para a esquerda, tu deves apertar a tecla 1 (um) e quando a flecha apontar para a direita tu deves apertar a tecla 0 (zero). Deves fazer isso da forma mais rápida e correta que conseguires. Está claro? Podemos começar?"

Logo após o Teste Simon de Flechas controle, era aplicado o teste de flechas laterais, com duração de 3 minutos em média. A fala para as crianças seguia os mesmos moldes do teste anterior: "Agora o teste é novamente de flechas e elas continuam apontando para a esquerda ou direita. A diferença é que elas estarão em lugares diferentes da tela. Não importa em que lugar ou lado da tela as flechas estão; o que importa é a direção para a qual ela aponta, ok? Continua valendo a mesma regra: flecha apontando para a esquerda, tecla 1(um); flecha apontando para a direita, tecla 0(zero). Lembre de fazer isso da forma mais rápida e correta que conseguires. Está claro? Podemos começar?"Ao final da testagem era agradecida a presença da criança e esta retornava a sua sala de aula.

\section{RESULTADOS}

Para testar as hipóteses de que (1) falantes bilíngues possuem melhor controle inibitório em tarefa não linguística do que monolíngues, e que (2) bilíngues de escola possuem controle de inibição tão eficaz quanto os bilíngues de casa, conduzimos uma série de análises estatísticas. Primeiramente, as médias de tempo de respostas corretas na tarefa Simon, que são apresentadas na Tabela 1, foram submetidas a uma ANOVA de Medidas Repetidas 3 X 3 X 2 com congruência (condição de controle, congruente ou incongruente) como o fator entre sujeitos do mesmo grupo (within-subjects factor), e grupo linguístico (bilíngue de casa, bilíngue escolar e monolíngue) e idade (crianças de 9 ou 12 anos) como fatores entre sujeitos de diferentes grupos (between-subjects factor).

A análise produziu um efeito principal (main effect) de congruência, $F(2,102)=66,3, M S E=19302,7, p<, 01$, sugerindo que, de uma forma geral, todos os grupos, e de ambas idades, responderam mais rapidamente a condição de controle $(M=538,2)$, seguida da condição congruente $(M=812,5)$, e por fim a incongruente $(M=836,7)$. Porém, mais interessante, a análise também produziu interações significativas entre os fatores congruência e

Organon, Porto Alegre, nº 51, julho-dezembro, 2011, p. 19-38 
grupo linguístico $(F(4,102)=5,7, M S E=19302,7, p<, 01)$ e congruência e idade $(F(2,102)=7,7, M S E=19302,7, p<, 01)$. Somado a esses efeitos acima citados, a análise identificou ainda uma interação significativa entre congruência, grupo linguístico e idade $(F(4,102)=2,5, M S E=19302,7, p<, 05)$, confirmando a relevância deste estudo.

\begin{tabular}{|c|c|c|c|c|c|c|}
\hline & \multicolumn{2}{|c|}{ Bilíngüe de casa } & \multicolumn{2}{c|}{ Bilíngue de escola } & \multicolumn{2}{c|}{ Monolíngue } \\
\hline & 9 anos & 12 anos & 9 anos & 12 anos & 9 anos & 12 anos \\
\hline Controle & $577,5(79,3)$ & $535,3(101)$ & $539,9(79,6)$ & $476,9(74,2)$ & $612,9(145,3)$ & $487(117,9)$ \\
\hline Congruente & $1196,5(406,7)$ & $769,1(260,2)$ & $718,8(153,9)$ & $657,2(182)$ & $917,8(417,4)$ & $615,5(97,3)$ \\
\hline Incongruente & $1150,6(272,7)$ & $838,9(257,5)$ & $769,6(122,4)$ & $612,7(89,8)$ & $1010,5(257,7)$ & $638,3(64,9)$ \\
\hline
\end{tabular}

Tabela 1: Médias e desvio padrão (DP) de tempo de reação por grupo linguístico e faixa etária nas três condições da tarefa Simon.

A fim de aprofundar as análises e esclarecer a natureza e a direção dessa interação entre os três fatores, os resultados foram submetidos a mais uma ANOVA de Medidas Repetidas, na qual os grupos de idades foram considerados separadamente. Tal análise nos permite averiguar se a interação entre os três fatores provém da diferença de idade entre os grupos. Assim, conduzimos duas análises adicionais do tipo 3 $\mathrm{X} 3$, usando congruência como fator entre sujeitos do mesmo grupo (within-subjects factor), e grupo linguístico como fator entre sujeitos de diferentes grupos (between-subjects factor). Os resultados demonstraram uma interação significativa entre congruência e grupo linguístico apenas no grupo de 9 anos, $F(4,50)=5,1, M S E=23032,2, p<, 01$. No grupo de 12 anos, a interação não foi significativa, $F(4,52)=1,6, M S E=$ $15716,8, p=, 176$. A presença de uma interação significativa no grupo de crianças de 9 anos e ausência no grupo de 12 anos sugere que há uma diferença em termos de controle inibitório entre os grupos linguísticos (bilíngues de casa, de escola e monolíngues) na idade de 9 anos, mas não de 12 anos. Para finalmente estabelecer quais grupos linguísticos diferem em termos de controle inibitório (no grupo de 9 anos), conduzimos uma serie de três testes-t independentes analisando as respostas de cada grupo linguístico nas condições de controle, congruentes e incongruentes. Vale ressaltar que o grupo de 12 anos não foi submetido a essas mesmas análises porque não houve interação significativa entre congruência e grupo linguístico nessa idade.

Organon, Porto Alegre, nº 51, julho-dezembro, 2011, p. 19-38 


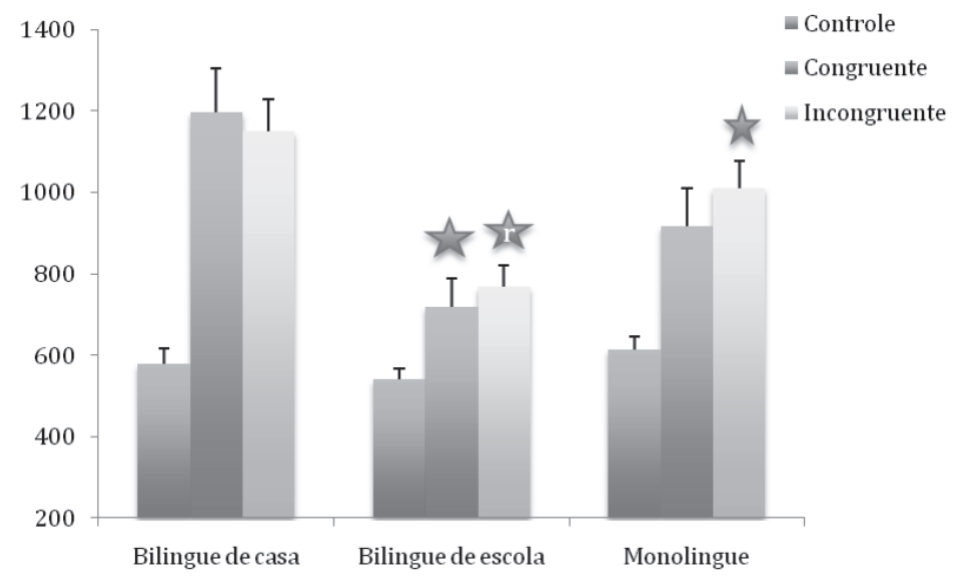

Figura 1. Tempo de resposta, em milisegundos, de cada grupo linguístico de 9 anos de idade na tarefa Simon.

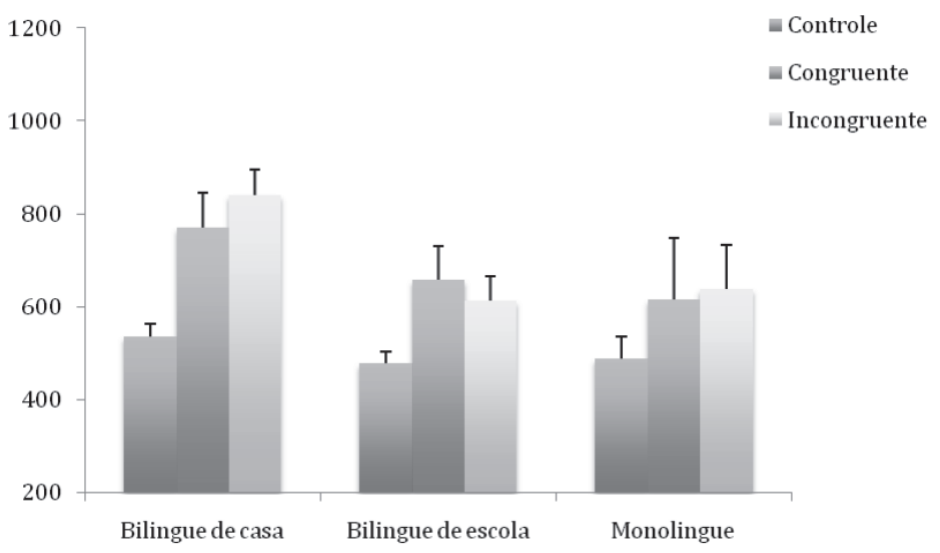

Figura 2. Tempo de resposta, em milisegundos, de cada grupo linguístico de 12 anos de idade na tarefa Simon.

No primeiro teste-t, comparamos o grupo de bilíngues de casa com os monolíngües e nenhum efeito significativo foi encontrado (todos os $p s$ $>, 05$ ), sugerindo que o tempo de resposta desses dois grupos não diferem em cada uma das condições de congruência. Ou seja, bilíngues de casa e monolíngues demonstraram níveis de controle inibitório similares. Não houve vantagem bilíngue, nem monolíngue. Esse resultado Organon, Porto Alegre, nº 51, julho-dezembro, 2011, p. 19-38 
difere dos resultados apresentados em outros estudos que evidenciam diferenças em termos de controle inibitório entre crianças bilíngues de casa e monolíngües (BIALYSTOK, 2001). Um dos motivos pode ser uma diferença entre as características dos bilíngues de casa de outros estudos e os do presente estudo. Na discussão (abaixo) abordaremos tal possibilidade de forma mais aprofundada.

No segundo teste-t, comparamos os bilíngues de escola com os monolíngues. Nessa análise, apenas o tempo de resposta na condição incongruente gerou resultados significativos, $t(20)=-3,0$, $p<, 01$. Nesse caso, os bilíngues de escola $(M=769,6)$ responderam à condição incongruente com mais rapidez do que os monolíngues $(\mathrm{M}=1010,5)$. Sugere-se então, que os bilíngues de escola demonstraram melhor capacidade de lidar com conflito de informação não linguística e, portanto, apresentaram melhor controle inibitório. Esse resultado replica dados obtidos em outros estudos cujos bilíngues obtiveram melhor desempenho que monolíngues em tarefas como a Simon. O resultado presente difere dos resultados anteriores, pois envolve bilíngues de escola e não de casa, como a maioria dos estudos de cunho linguístico e psicolinguístico tem apresentado (Bialystok, 2005 entre outros).

Por fim, comparamos os dois grupos de bilíngues, de casa e de escola, nas três condições de congruência. Essa análise também nos permite testar a hipótese de que bilíngues de escola teriam desempenho ao menos tão eficiente quanto os bilíngües de casa em tarefas de controle de interferência não linguística. Conforme previsto, os bilíngues de escola responderam com mais rapidez que os bilíngues de casa tanto na condição congruente quanto na incongruente. Mais precisamente, os bilíngues de escola $(\mathrm{M}=1196,5)$ foram aproximadamente 478 ms mais rápidos que os bilíngues de casa $(\mathrm{M}=718,8)$ na condição congruente, $t(18)=3,9, p<, 01$. Na condição incongruente, os bilíngues de escola $(\mathrm{M}=1150,6)$ foram $381 \mathrm{~ms}$ mais rápidos que os bilíngues de casa $(\mathrm{M}=769,6), t(18)=4,4, p<, 01$. Esse resultado dá suporte a nossa hipótese e indica que o bilinguismo escolar pode sim proporcionar as mesmas vantagens cognitivas observadas em crianças de contexto familiar bilíngue em termos de controle inibitório em tarefas não linguísticas. Na seção seguinte, discutiremos esses resultados e suas implicações mais detalhadamente. 


\section{Efeito Simon}

Em uma última e separada série de análises, comparamos o tamanho do efeito Simon entre os grupos linguísticos (também separados por idade, pois as análises anteriores já informaram a existência de uma diferença). O Efeito Simon é a diferença em tempo de reação entre as respostas da condição incongruente e da condição congruente [(tempo de resposta incongruente) - (tempo de resposta congruente)]. Resultados positivos indicam tempo de resposta mais longo na condição incongruente, e, portanto, a presença do efeito Simon, enquanto resultados negativos indicam tempo de resposta mais curto na condição incongruente e a ausência do efeito Simon. Na série de análises conduzida, nenhum resultado foi significativo (todos os $p s>, 05$ ), ou seja, o efeito Simon teve semelhante tamanho em todos os grupos linguísticos e idades. Mais especificamente, as comparações entre bilíngues e monolíngues de ambos 9 e 12 anos indicam que a diferença em tempo de resposta entre as condições incongruentes e congruentes não difere entre os grupos.

Na seção seguinte, faremos uma discussão geral sobre os resultados aqui apresentados e suas implicações para as pesquisas no campo de bilinguismo e controle inibitório.

\section{DISCUSSÃO}

O objetivo deste estudo foi investigar se as funções executivas, em especial o controle inibitório, é mais desenvolvido em crianças bilíngues do que monolíngues como mostram em estudos anteriores, e principalmente se o contexto escolar bilíngue proporcionaria às crianças desempenho parecido ao dos bilíngues de casa em termos de controle inibitório.

Uma das hipóteses que norteou esta pesquisa foi de que falantes bilíngues possuem melhor controle inibitório em tarefa não linguística do que monolíngues. Ao compararmos o grupo de bilíngues de casa com o grupo de monolíngues desta amostra, foi possível verificar que as médias dos tempos de resposta desses dois grupos não diferiram em nenhuma das condições de congruência, ou seja, bilíngues de casa e monolíngues demonstraram níveis de controle inibitório similares. Não houve vantagem para nenhum dos grupos. Esse resultado difere dos resultados apresentados em outros estudos que evidenciam diferenças 
em termos de controle inibitório entre crianças bilíngues de casa e monolíngues (BIALYSTOK, 2001a). Um dos motivos pode ser uma diferença entre as características dos bilíngues de casa de outros estudos e os do presente estudo. Os bilíngues de casa que constituíram a amostra investigada neste estudo, apesar de terem contato diário com a língua alemã ou com o hünsrickisch através da interação com seus avôs, ao falarem ao telefone, com os pais e amigos em algumas conversas diárias e, até mesmo, escutando a língua na comunidade e na escola, na maioria desses momentos não manipulam essa língua. Conforme Baker (2006), a educação bilíngue de manutenção visa manter a língua proveniente da família, da comunidade da criança. Entretanto, essa proposta pode ter duas vertentes: a manutenção estática dessa língua da família ou a manutenção com vistas ao desenvolvimento. Parece-nos que a segunda língua nessa comunidade investigada está mais focada na manutenção estática, ou seja, a língua não é manipulada, desenvolvida ou estudada com profundidade, apenas mantida na forma de interações do dia a dia. Bialystok e Majumder (1998) relatam que as vantagens identificadas em tarefas metalinguísticas dependem do grau de bilinguismo dos sujeitos, ou seja, o bilinguismo deve estar em um alto nível de desenvolvimento para que haja vantagens identificáveis entre monolíngues e bilíngues. Os resultados relatados aqui sugerem que é necessário não somente uma exposição precoce a segunda língua, mas também que essa seja uma exposição intensa e com vistas ao desenvolvimento. Caso contrário, os benefícios cognitivos relacionados às funções executivas não se manifestam.

Ao comparamos os bilíngues de escola com os monolíngues, encontramos resultados diferentes. Nesse caso, os bilíngues de escola responderam à condição incongruente com mais rapidez do que os monolíngues. Sugere-se então, que os bilíngues de escola demonstraram melhor capacidade de lidar com conflito de informação não linguística e, portanto, apresentam melhor controle inibitório. Esse resultado replica dados obtidos em outros estudos cujos bilíngues tem melhor desempenho que monolíngues em tarefas como a tarefa Simon (BIALYSTOK e MARTIN, 2004; MARTIN-RHEE e BIALYSTOK, 2008). Mesmo assim, o presente resultado difere dos resultados anteriores, pois envolve bilíngues de escola e não de casa, como a maioria dos estudos de cunho linguístico e psicolinguístico tem apresentado (BIALYSTOK, 2004, 2005 entre outros). Baseando-nos nesse resultado favorecendo os bilíngues escolares em comparação aos monolíngues, sugerimos que 
o bilinguismo escolar também proporciona aos bilíngues a possibilidade de desenvolvimento cognitivo avançado, nesse caso específico, do controle inibitório. Em resumo, os resultados parecem responder a primeira hipótese apresentada nesta pesquisa, pois os bilíngues escolares obtiveram melhores resultados que os monolíngues na condição incongruente dos testes.

Em relação à outra hipótese investigada, de que os bilíngues escolares teriam melhor desempenho na tarefa Simon do que os bilíngues de casa, os resultados também parecem confirmar a hipótese. Os bilíngues de escola foram mais rápidos que os bilíngues de casa nas condições congruentes e incongruentes dos testes. Esses resultados trazem um novo olhar sobre as pesquisas envolvendo sujeitos bilíngues. As crianças que são expostas à segunda língua em contexto escolar, até hoje não investigadas nas pesquisas, parecem ter desenvolvido mecanismos cognitivos de forma muito intensa nessa exposição diária a segunda língua. Apesar de não terem a segunda língua como uma língua de uso na comunidade nem na família, o uso diário dessa língua, ainda que só no ambiente escolar, parece conferir vantagens em relação ao desenvolvimento das funções executivas.

Parece-nos que a necessidade imposta pela educação bilíngue de prestígio, de manipular informações e conhecimentos na segunda língua através de atividades de codificação, decodificação, memorização e evocação dessa língua, juntamente com a necessidade de desenvolver a segunda língua através das habilidades de leitura, compreensão oral e escrita, produção oral e escrita, fornece às crianças desse grupo linguístico maior controle sobre a atenção seletiva, bem como, controle inibitório mais desenvolvido.

Os resultados obtidos respondem a questão levantada: "o bilinguismo escolar também proporciona vantagens cognitivas como o bilinguismo societal ou familiar?". A evidência parece indicar que o bilinguismo escolar pode sim proporcionar as mesmas vantagens cognitivas observadas em outros estudos envolvendo crianças consideradas bilíngues nativas.

Resumindo, os resultados desta pesquisa nos permitem concluir que crianças expostas ao bilinguismo escolar, quando comparadas com crianças monolíngues e com crianças bilíngues oriundas de comunidades de fala bilíngues, foram mais rápidas para responder aos

Organon, Porto Alegre, n 51, julho-dezembro, 2011, p. 19-38 
estímulos congruentes e incongruentes da tarefa Simon demonstrando semelhança com estudos anteriores, principalmente no que diz respeito às questões de controle inibitório. É importante lembrar que os efeitos do bilinguismo escolar apresentado referem-se às crianças de 9 anos apenas. As crianças de 12 anos não demonstraram o mesmo padrão de resultados. Uma possível explicação para a ausência de efeito aos 12 anos é que, talvez, nessa idade os bilíngues familiares já apresentem o mesmo desempenho dos bilíngues escolares. É possível que, em três anos, esses bilíngues alcancem um nível de exposição à segunda língua que é comparável aos bilíngues escolares.

Ressalta-se ainda que, apesar de corroborar dados de outras pesquisas, esta amostra é inédita por utilizar um grupo linguístico diferente daqueles utilizados nas pesquisas cognitivas até então.

Entre as limitações deste trabalho, inclui-se a necessidade de novos estudos dentro do contexto de educação bilíngue, para que possamos comparar resultados obtidos nesta amostra. Além disso, é necessário que em futuros estudos se possa controlar a frequência de uso da segunda língua no grupo de bilíngues de casa. Outra necessidade para futuros estudos é que a amostra de cada grupo linguístico possa ser proveniente de mesma classe social, econômica e cultural a fim de controlar diferenças que possam vir a interferir nos resultados finais.

Finalmente, esperamos que os resultados evidenciados neste estudo possam contribuir com futuras pesquisas e estimular novos estudos sobre os benefícios do bilinguismo e da educação bilíngue, tanto no que se refere às áreas da Psicolinguística e da Neurolinguística, quanto na área da Educação.

\section{BIBLIOGRAFIA}

BAKER, Colin. Foundations of Bilingual Education and Bilingualism. 4th ed.Multilingual Matters, 2006.

BIALYSTOK, Ellen. Factors in the growth of linguistic awareness. Child Development, v. 57, p. 498-510, 1986.

BIALYSTOK, Ellen. Levels of bilingualism and levels of linguistic awareness. Developmental Psychology, v. 24, p. 560- 567, 1988. BIALYSTOK, Ellen. Bilingualism in development: Language, literacy, and cognition. New York: Cambridge University Press, 2001a. 
BIALYSTOK, Ellen. Metalinguistic aspects of bilingual processing. Annual Review of Applied Linguistics, v.21, p. 169-181, $2001 \mathrm{~b}$.

BIALYSTOK, Ellen. Bilingualism. John Wiley \& Sons, Ltda, v. 1, p.559-572, 2010.

BIALYSTOK, Ellen; CRAIK, Fergus. Cognitive and Linguistic Processing in the Bilingual Mind. Current Directions in Psychological Science, v.19, p.19-23, 2010.

BIALYSTOK, Ellen; CRAIK, Fergus I. M.; KLEIN, Raymond; VISWANATHAN, Michele. Bilingualism, aging and cognitive control: Evidence from the Simon Task. Psychology \& Aging, v.19, p.290- 303, 2004.

BIALYSTOK, Ellen; MAJUMDER, Shilpi. The relationship between bilingualism and the development of cognitive processes in problem solving. Applied Psycholinguistics. v 19, p.69- 85, 1998.

BIALYSTOK, Ellen; MARTIN, Michelle. Attention and inhibition in bilingual children: Evidence from the dimensional change card sort task. Developmental Science, v. 7, p. 325-339, 2004.

BIALYSTOK, Ellen; MARTIN, Michelle; VISWANATHAN, Mythili. Bilingualism across the lifespan: the rise and fall of inhibitory control. International Journal of Bilingualism, v. 9, n. 1, p. 103-119, 2005.

BIALYSTOK, Ellen; CRAIK, Fergus. I. M.; RYAN, Jennifer. Executive control in a modified anti-saccade task: Effects of aging and bilingualism. Journal of Experimental Psychology: Learning, Memory, and Cognition, v. 32, p.1341-1354, 2006.

BIALYSTOK, Ellen; SHAPERO, Dana. Ambiguous benefits: The effect of bilingualism on reversing ambiguous figures. Developmental Science, v.8, p.595-604, 2005.

BILLIG, Johanna D. Bilinguismo e Envelhecimento: efeitos no controle cognitivo. Dissertação ( Mestrado em Linguística Aplicada) - Faculdade de Letras, UFRGS, Porto Alegre, 2009.

BLAIR, Clancy; ZELAZO, Philip D.; GREENBERG, Mark. T. The measurement of executive function in early childhood. Developmental Neuropsychology, v. 28, p. 561-571, 2005.

BRENTANO, Luciana de S. Qual o momento ideal para seu filho iniciar a aprendizagem de uma nova língua? Artigo de divulgação para o jornal NH., Novo Hamburgo, R.S. 2009.

CARLSON, Stephanie M.; MELTZOFF, Andrew N. Bilingual experience and executive functioning in young children. Developmental Science, v. 11, n.2, p. 282-298, 2008.

Organon, Porto Alegre, ํำ51, julho-dezembro, 2011, p. 19-38 
CROMDAL, Jakob. Childhood bilingualism and metalinguistic skills: Analysis and control in young Swedish-English bilinguals. Applied Psycholinguistics, v.20, p.1-20, 1999.

DIAMOND, Adele. The early Development of Executive Functions. In: BIALYSTOK, E.; CRAIK, F. (ed) Lifespan Cognition: Mechanisms of change. New York: Oxford University Press, 2006.

GALAMBOS, Sylvia J.; GOLDIN-MEADOW, Susan. The effects of learning two languages on levels of metalinguistic awareness. Cognition, v. 34 (1), p. 1-56, 1990.

GALAMBOS, Sylvia. J.; HAKUTA, Kenji. Subject-specific and taskspecific characteristics of metalinguistic awareness in bilingual children. Applied Psycholinguistic, v.9, n.2, p. 141-162, 1988. GAWRYSZEWSKI, Luis de G. et al. Memória de longo prazo modulada pela memória de curto prazo. Paidéia, v.18 (40), p.331-339, 2008. MARTIN-RHEE, Michelle M.; BIALYSTOK, Ellen. The development of two types of inhibitory control in monolingual and bilingual children. Bilingualism: Language and Cognition, v. 11, n. 1, p. 81-93, 2008. POULIN- DUBOIS, Diane; et AL. The effects of bilingualism on toddlers'executive functioning. Journal of Experimental Child Psychology, v.1, p. 1- 13, 2011.

VAN ASSCHE, Eva; DUYCK, Wouter; HARTSUIKER, Robert J.; DIEPENDAELE, Kevin. Does Bilingualism change native- language reading? Cognate effects in a sentence context. Psychological Science, v.20 (8), p.923-927, 2009.

ZELAZO, Philip D., The development of conscious control in childhood. Trends in Cognitive Sciences, V. 8 (1), p. 12-17, 2004.

ZELAZO, Philip D., The Dimensional Change Card Sort (DCCS): a method of assessing executive function in children. Nature Protocols, v.1, p. 297-301, 2006. 